\title{
A construção do diagnóstico diferencial à luz da psicopatologia fenomenológica
}

\author{
Ana Maria Thomé1 \\ Guilherme Peres Messas²
}

\section{Resumo}

O presente artigo se detém sobre a construção do diagnóstico diferencial ao estudar o caso de uma mulher de 43 anos, branca, sem filhos, denominada T., atendida na atenção primária pelas equipes da Estratégia Saúde da Família (ESF) e do Núcleo de Apoio à Saúde da Família (NASF). Para isso, adota a Psicopatologia Fenomenológica como referencial teórico, procurando analisar os diferentes diagnósticos psicopatológicos propostos pelos profissionais de saúde responsáveis pelo acompanhamento do caso ao longo do tempo. $\mathrm{O}$ estudo conclui que a Psicopatologia Fenomenológica é o referencial teórico cujos princípios, como a importância do acompanhamento longitudinal e a valorização da totalidade dos eventos biográficos, coincidem com as diretrizes observadas na saúde pública brasileira, de acordo com o que é preconizado pelo Sistema Único de Saúde (SUS).

Palavras-chave: Psicopatologia Fenomenológica; Diagnóstico diferencial; Esquizofrenia; Discussão de caso; Saúde mental na atenção primária.

\footnotetext{
${ }^{1}$ Psicóloga. Especialização em Psicopatologia e Saúde Pública pela Faculdade de Saúde Pública da Universidade de São Paulo - FSP/USP. Especialização em Neuropsicologia pela Faculdade de Medicina da Universidade de São Paulo - FMUSP. Coordenadora Técnica do Centro de Atenção Psicossocial - CAPS Adulto II Brasilândia. Email: anamariathome@yahoo.com

2 Médico psiquiatra, mestre em Medicina e doutor em Psiquiatria pela Universidade de São Paulo. Membro Fundador e Presidente da Sociedade Brasileira de Psicopatologia FenômenoEstrutural. Coordenador do Curso de Especialização em Psicopatologia Fenomenológica da Faculdade de Ciências Médicas da Santa Casa de São Paulo. Membro da Câmara Técnica do Conselho Regional de Medicina do Estado de São Paulo. Email: messas@fenomenoestrutural.com.br
} 


\title{
Construction of differential diagnosis under the light of phenomenological psychopathology
}

\begin{abstract}
This article dwells on the construction of the differential diagnosis when studying the case of a woman aged 43, white, childless, called T., served in primary care teams of the Family Health Strategy - ESF and Support Center Family Health - NASF. For this, adopts the Phenomenological Psychopathology as theoretical basis, trying to analyze the different psychopathological diagnoses proposed by health professionals responsible for monitoring the case over time. The study concludes that the Phenomenological Psychopathology is the theoretical principle which, - since it gives importance to longitudinal follow-up and recovery of all the biographical events - coincide with the guidelines found in the Brazilian public health, according to what is recommended by the National Health System - SUS.
\end{abstract}

Keywords: Phenomenological Psychopathology; Differential diagnosis; Schizophrenia; Case discussion; Mental health in primary care.

\section{A construção do diagnóstico diferencial à luz da psicopatologia fenomenológica: o caso $\mathrm{T}$.}

O caso que segue foi atendido na atenção primária conjuntamente pelas equipes da Estratégia Saúde da Família (ESF) e do Núcleo de Apoio à Saúde da Família (NASF) no ano 2009. Trata-se de uma paciente do sexo feminino, 43 anos, solteira e sem filhos.

As informações do presente estudo advêm do meu breve contato com T., bem como das informações constantes em seu prontuário médico ${ }^{3}$. O objetivo é apresentar o caso clínico promovendo a discussão do diagnóstico diferencial, tendo como referencial teórico a psicopatologia fenomenológica.

\footnotetext{
${ }^{3}$ Todas as passagens do texto em primeira pessoa do singular tem como sujeito a primeira autora, responsável pelo atendimento direto da paciente estudada. As análises do caso, de responsabilidade de ambos os autores, recebem a primeira pessoa do plural.
} 
Conforme dados do prontuário da paciente, foi iniciativa da enfermeira da equipe de ESF que acompanha a família levar o caso de T. para discussão com a equipe do NASF da qual eu, naquele período, era a psicóloga. O relato em prontuário indica que T. se encontrava acamada há oito anos, após queda da própria altura, com lesão no quadril. A conseqüência deste longo período de restrição ao leito se traduziu no diagnóstico de uma deformidade importante na caixa torácica, atrofia da musculatura dos membros e dor nas articulações.

Meu primeiro estranhamento ao discutir o caso com a equipe da ESF se deteve sobre o porquê - à época do acidente - de T. ou seus familiares próximos não buscarem um serviço médico para tratar a lesão no quadril que a limitou tão significativamente. A justificativa apresentada foi a presença de um quadro de Síndrome do Pânico (sic), que restringiu o contato de T. com outras pessoas, bem como a impossibilidade de aderir às medidas de cuidado à saúde.

Era comum T. referir que sofria de Síndrome do Pânico, motivo pelo qual, acreditava, não conseguira mais deixar o leito, alimentar-se adequadamente ou desenvolver atividades anteriormente cotidianas, como trabalho e contato com terceiros. A paciente informou que chegou a fazer uso de medicação psiquiátrica para tratar o suposto quadro de pânico, mas suspendeu a medicação por conta própria, em razão de "efeitos adversos".

Além do quadro de deformidade física, T. apresentava magreza extrema e importante anemia. Todavia, esses sinais pareciam não incomodar a paciente e sua cuidadora mais próxima - a mãe. As duas pareciam se adaptar com certa facilidade na medida em que T. "descobria” o que lhe fazia mal.

Em meu primeiro contato, bem como em todas as outras ocasiões em que estivemos juntas, a ênfase das queixas era a perturbadora sensação de medo que T. tentava eliminar adotando comportamento evitativo, a partir da restrição de contato com o mundo externo.

“Começou com uma depressão leve, há dez anos" (em 1999). A imprecisão temporal dos relatos de T. confundiam-me a ponto de eu procurar, obstinadamente, reconstruir a anamnese ao longo dos encontros. Quando apontei para T. a aparente contradição que seu novo enfoque trazia à tona - o de uma depressão leve - ela corrigiu-me. Nem depressão, nem queda: seu adoecimento começou quando, há dez anos, comeu um doce que a deixou "muito esquisita por dentro". T. concluiu: "o corpo parou e não fiz mais nada".

Neste período, passou a se alimentar apenas de chá e bolacha. Segundo a mãe, adotou este padrão alimentar por aproximadamente três anos. O primeiro médico de família que a avaliou, em 2005, indicou medicação psicotrópica para Síndrome do Pânico. Conforme T., a medicação a fez vomitar (sic). 
O alimento que, segundo a paciente, desencadeou sua ruína era um doce de leite dado por uma sobrinha a quem considerava uma de suas poucas amigas. Após comê-lo, nunca mais saiu de casa. T. acredita que a sobrinha colocou "uma coisa ruim" no doce. No entanto, ressalta que "outras pessoas comeram o doce, apenas para mim fez mal". Acredita que a motivação para tal ato foi inveja, já que sua parente era muito gorda. Nunca mais conversaram, cortando relações. Mais uma vez é imprecisa no tempo e refere que não a vê há vinte anos (desde 1989). Sentiu raiva e medo da sobrinha, uma de suas poucas companhias com quem conversava muito e andava sempre junto.

A partir disso, passou a auto-impor restrições alimentares severas, adotadas - sem críticas ou contraposições - pela mãe. T. passou a aceitar apenas a comida preparada pela mãe, limitando, no entanto, quais alimentos poderiam constar em seu exíguo cardápio. Não come carne e nenhum alimento que contenha ovo. Nem doces, nem leite. Pão, apenas o caseiro, preparado pela mãe, nunca o de padaria, porque sabe que "colocam coisas que fazem mal".

Queixa-se de dor de barriga, mas percebe a ligação deste sintoma com a sensação de medo: "minha cabeça não bate bem". Sofre constantemente de diarréia, "porque estou com medo sempre". Teme ficar só e aponta que o que a alivia é "ficar quietinha". Sente-se fraca, passando o dia na cama, na maior parte do tempo deitada: sentar a deixa tonta. Não sente sono e refere ser comum passar as noites olhando para o teto. Quando questionada sobre quais pensamentos vêm à cabeça nestes momentos, evade-se: "penso besteira". Posteriormente, confessa ter medo de enlouquecer. Evita me falar dos seus sonhos, observando que antes de adoecer, sonhava: "mas não sei o que sonhava". Todavia, a riqueza narrativa de T. está centrada em suas queixas dos penosos eventos corporais, com foco na percepção do dentro e fora. Água que entra e embrulha o estômago, café que entra e faz mal, meu espirro - ela comenta - que se deve ao ar poluído de São Paulo.

Numa das ocasiões comentou que desejava engordar. Observa que o máximo de peso que obteve foi 42 quilos. Atualmente acredita pesar 36 quilos. Descreve sua figura como "aquelas crianças do nordeste, com anemia, que não conseguem se desenvolver". Aliás, a figura de T. não é agradável de ser olhada: lembra-me um sagui, e parece atestar o desconforto que descreve em seus relatos, a ponto de, em algumas ocasiões, nausear-me. Provoca, simultaneamente, curiosidade e cansaço.

Dores no corpo todo que pioram com o calor ou frio intenso. Ao fazer uso de polivitamínico, sente-se melhor. Porém, passou a evitá-lo por ter medo de que virasse veneno em seu estômago. A própria descrição da Síndrome de Pânico traduz-se em sensações de aniquilamento físico: coração que acelera, 
dores nos ossos, estômago "embrulhado", sensação terrível que sobe dos pés à cabeça como se fosse enterrada viva. E medo. Desconfia de todos, menos da mãe.

T. apresentou-se lúcida e orientada ao longo de todas as entrevistas. Conta que, anteriormente ao colapso, fabricava bijuterias e, dezoito anos atrás, chegou a trabalhar como empregada doméstica em casa de família. Adorava chocolates e doce de leite. Não tinha medo de nada, até ficar depressiva. Descreve depressão como choro fácil e tristeza "sem porquê". Tristeza que a acompanhava no trabalho, onde pensamentos de cunho niilista e raiva de si mesma eram frequentes.

Uma das poucas distrações de T. é assistir à televisão, principalmente telejornais. É neles que parece reforçar a convicção latente em seus relatos de que o mundo é hostil. Mundo povoado de objetos externos aniquiladores, que invadem e deturpam o corpo. Ideia compartilhada pela mãe.

T. reclama da mudança do horário de verão, que "mexe com seu organismo". Quando, numa segunda ocasião, insisti para que a paciente revelasse o que costuma pensar durante as noites insones, conseguiu admitir que as notícias do jornal na televisão a impressionam, especialmente catástrofes naturais. A paciente enfocou as recentes notícias sobre o terremoto no Chile e outros episódios trágicos, devastadores: furacões, maremotos, tempestades: um mundo implacável.

Sobre o pai, T. mostra-se evasiva e irritada ao abordar o assunto. Conheceu o pai, mas este foi viver com outra família que formou numa cidade distante para onde, rotineiramente, viajava por motivo de trabalho. Com a saída do pai, sua mãe teve de trabalhar como doméstica e, posteriormente, como cozinheira num restaurante. Aposentou-se na ocasião da morte do seu chefe. Quando questionada qual o prato que mais gostava de fazer, a mãe de T. não soube responder.

Foi possível notar que quando o assunto versava sobre os objetos de medo de T., a mãe aproximava-se, externando seus próprios temores, semelhantes aos da filha. Na ocasião em que falávamos sobre catástrofes naturais, revelou sentir medo do escuro, da chuva e de ladrão.

Como T., o medo era de tudo que vinha do externo e, sorrateiramente, invadia o interno. Para combater o medo do escuro, mantinha as luzes acesas. Tinha convicção de que a chuva destrói: "meu patrão morreu numa enchente". Como a filha, diante da sensação de medo, sucumbia à dor de barriga. Mãe e filha pareciam comungar num mesmo código de medo e suplício corporal. 


\section{Discussão}

Inicialmente, detenhamo-nos sobre as aparentes contradições na sequência temporal dos eventos narrados por T. que reconstroem sua história de incapacitação. Sendo o testemunho pessoal a base da análise fenomenológica (Messas, 2010), acreditamos que tais contradições, ao invés de opacizar, permitam o lançamento de hipóteses sobre o quadro da paciente, sustentando a análise do fato patológico, bem como a construção do diagnóstico diferencial que, por ora, ambiciono estabelecer.

Ainda que a narrativa de T., permeada de incoerências cronológicas, possa se tratar de simples equívoco, Messas (2010, p. 9) pontua que "o passado é um subproduto do presente, sem autonomia ontológica". Questiona o autor: "como invocar o passado se este é uma modalidade especial do presente e, consequentemente, existe apenas um retrato presente em estado contínuo de recriação?" (Messas, 2010, p. 8). Conclui que os dados de um relato se forjam a partir da ressonância que determinada vivência do investigando produz sobre a vivência do investigador: eis a matéria sobre a qual o psicopatólogo fenomenológico é convocado a debruçar-se.

Valemo-nos, para tanto, do testemunho de T. permeado de uma inexata e reveladora cronologia. Inexatidão que, inicialmente, aponta para um aspecto expressivo de seu relato: 1989 é o ano reiteradamente estabelecido por ela onde ocorre uma tímida, mas importante ruptura. Trata-se do início do comportamento de restrição alimentar - primeiro sinal indicador da emersão de patologia que comprometerá severamente a paciente, característica que marcará seu quadro mórbido até os dias de hoje. Além disso, T. localiza nesta mesma época, e por diversas vezes, o "rompimento" com a sobrinha - figura afetivamente relevante para a paciente.

Estes aparentes "equívocos" narrativos sugerem o desvelamento de sucessivos "abalos" na frágil edificação existencial de T., ainda numa data anterior a 1999 - ano por ela estabelecido como "marco inaugural" de sua ruína pessoal. Cabe salientar que 1999 é o ano em que T. consome o doce de leite oferecido pela sobrinha que a deixaria "esquisita por dentro". Com isso, aventamos a possibilidade de que o que se percebe como "engano" revele, na verdade, o advento do comprometimento mental de T. já em 1989, época em a paciente não vivenciava a experiência de enfermidade, percebendo-se "saudável e sem medo algum". O último dos anos de 90 talvez seja o período em que a paciente vivencie o agravo incontornável de uma ruptura iniciada dez anos antes, traduzida pela convicção de que fora envenenada por uma pessoa que participava intimamente de sua vida. 
A construção de uma linha de tempo resumindo - em forma de esquemaa rica narrativa da paciente nos parece o recurso ideal para destacar a sequência de abalos de intensidade variada ao longo da existência de T., a partir da fratura, em 1989, que culminou no quadro mórbido atual - desafio aos profissionais de saúde responsáveis pela assistência ao caso.

Esta linha de tempo truncada é reveladora, na medida em que nos permite a visualização de um aspecto caro ao presente estudo. Ou seja, acompanhar a emergência do que em psicopatologia fenomenológica denominamos "Processo", conceito que indica a modificação permanente em determinado psiquismo, contrapondo-se à noção de desenvolvimento (Tamelini, 2007).

Além disso, o esboço da linha do tempo auxilia na construção, a partir do exercício de compreensão reflexiva, do diagnóstico diferencial com base no arcabouço teórico da psicopatologia fenomenológica. Ainda que o diagnóstico proposto anteriormente seja uma tentativa coerente de compreender do que T. sofria, compatível com o conjunto de sintomas e sinais que tipificam os transtornos de humor e ansiedade contidos nos manuais de diagnósticos psiquiátricos, acreditamos que não contemple, nem caracterize adequadamente, a extensão do agravo mental de T..

Como justificativa para esta afirmação, apontamos um fato mencionado anteriormente que, acreditamos, não tenha sido considerado pelos profissionais que assistiram o caso até então: o de que a paciente teve sua linha vital fraturada em virtude de um processo, sendo seu quadro psicopatológico melhor explicado pelo diagnóstico de uma esquizofrenia altamente incapacitante.

Com isso, queremos dizer que o conjunto de sintomas e sinais percebidos pelo profissional que a acompanhava como síndrome do pânico (sic) seja, na verdade, o pródromo de um quadro severo de esquizofrenia, antecedido de crises de intensidades variadas. 
Linha do tempo construída de acordo com a narrativa dos eventos cronologicamente ordenados por T.

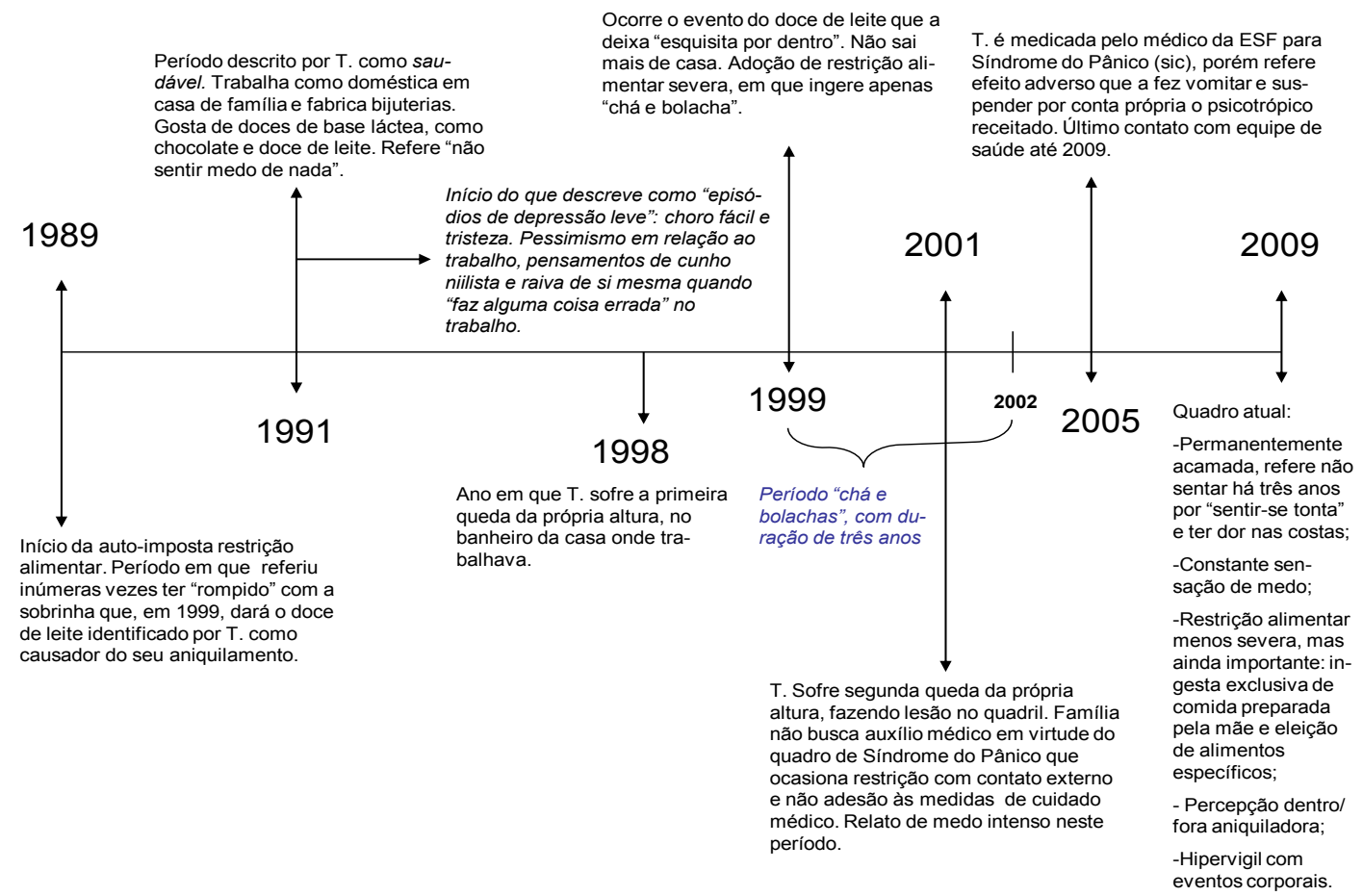

Nossa afirmação desconstruindo os diagnósticos anteriormente propostos e indicando um quadro de psicose processual exige apreciação cuidadosa. Insistimos na afirmação de que as hipóteses diagnósticas anteriormente pensadas possuíam o mérito de procurar compreender e tratar a restrição crescente que se estabeleceu de modo devastador na vida de T.. Para isso, o profissional recorreu ao que é preconizado nos manuais diagnósticos de transtornos mentais (APA, 2002; Sadock, 2006). Trata-se, portanto, de um aspecto que não deve ser compreendido apressadamente.

Tanto o "auto-diagnóstico" feito pela paciente - o de uma "depressão leve" - quanto a indicação de transtorno mental compatível com o quadro de "síndrome do pânico", cogitado em 2005 pelo médico da ESF, mostram-se coerentes com o conjunto de sintomas e sinais descritos nos grandes manuais da semiologia psiquiátrica (APA, 2002; Sadock, 2006; Dalgalarrondo, 2008). Se observarmos a descrição no "Manual Diagnóstico e Estatístico dos Transtornos Mentais - DSM-IV TR" (APA, 2002) tanto do conjunto das psicopatologias dos quadros de humor, como os de ansiedade, evocados por T. e pelo médico que procurou assisti-la, verificaremos que há uma cadeia de sintomas e sinais compatíveis com as duas hipóteses.

Dessa forma, tanto o Episódio Depressivo Maior, quanto o Transtorno Depressivo Maior e o Transtorno Distímico, são tipificados por sintomas e sinais como propensão ao choro, irritabilidade, ruminação obsessiva, ansiedade, 
fobias, preocupação com a saúde física, queixas de dores, apetite diminuído ou hiperfagia, insônia ou hipersonia, baixa energia ou fadiga, baixa auto-estima e sentimentos de desesperança. Já os transtornos de ansiedade e, mais especificamente, o Ataque de Pânico e Síndrome de Pânico, são caracterizados pelo medo intenso ou desconforto, acompanhados de um conjunto de sintomas somáticos ou cognitivos como palpitações, sudorese, tremores, dor ou desconforto torácico, náusea ou desconforto abdominal, calafrios, medo de perder o controle ou enlouquecer, entre outros.

No relato de T., é possível constatar a presença de grande parte dos sintomas e sinais compatíveis com as semiologias anteriormente evocadas, evidenciando, todavia, a constelação de sintomas e sinais de disfunção social, ocupacional, empobrecimento afetivo e a perda de vontade - indicadores comportamentais que podem apontar para a emersão de um quadro psicótico.

Importante ressaltar que a descrição de sintomas e sinais contidos nos manuais psiquiátricos não objetiva formar um conjunto que decodifique, a partir de determinado pressuposto teórico, o dinamismo de um evento psicopatológico. Ela visa simplesmente a descrever e catalogar conjuntos de sintomas e sinais em grandes redes psicopatológicas a partir de método empírico. Por esse motivo, a semiologia que caracteriza determinado transtorno mental se mostra insuficiente para a sustentação criteriosa de um diagnóstico diferencial como logramos aqui construir. Este exigirá do investigador o acompanhamento dos movimentos vitais de expansão e retração, os compreendendo interpretativa e singularmente.

Exige, ainda, a impressão do relato da vivência do sujeito na mnese do investigador (Messas, 2010, p.10). Tais aspectos apreendem a atenção do investigador sobre os eventos aparentemente não significativos do ciclo vital, bem como a eleição de determinada linha teórica que as signifique e compreenda.

Neste caso, o que encorajaria o presente estudo a sustentar que o diagnóstico de T. não está vinculado à grande cadeia de sintomas e sinais que caracterizam os transtornos do humor ou ansiedade, mas sim de um quadro psicótico grave? O inventário de sintomas psiquiátricos, tão em voga na atualidade, não se revelaria suficientemente adequado para estabelecer criteriosamente determinada hipótese diagnóstica?

Sim e não. Sim, na medida em que a detecção de sintomas e sinais é o primeiro passo para a psicopatologia fenomenológica, ciência que se vale integralmente do que é passível de ser apreendido pelo psicopatólogo. Não, se atentarmos para o fato de que os manuais diagnósticos se pautam pelo pragmatismo e restringem-se meramente à descrição e generalização de 
sintomas e sinais com o intuito de universalizá-los. Portanto, a simples evocação do conjunto de sintomas e sinais não é capaz de dar conta da análise acurada que a fenomenologia exige.

Queremos dizer, com isso, que a fenomenologia se baseia na descrição do fato patológico; todavia, vai além ao buscar desvendar as estruturas dadas pela descrição empírica de determinado fenômeno mórbido. Além disso, é a partir da análise da biografia de determinado indivíduo que poderemos compreender que um diagnóstico isoladamente não esgota a compreensão da totalidade existencial e diagnóstica do paciente.

Para compreensão do caso T., existem três possíveis alternativas lógicas. A primeira delas vai de encontro, exatamente, a diagnósticos excludentes. Ou seja, por essa perspectiva T., de fato, atravessou um episódio depressivo leve e, mais tarde, desenvolveu quadro compatível com transtorno de pânico, precedendo a esquizofrenia.

Uma segunda alternativa lógica vale-se do viés epistemológico, que atesta uma discordância entre duas formas de compreender os eventos patológicos, a partir de enfoques distintos; neste caso, a descrição dos sintomas que afetaram progressivamente $T$. indicariam as hipóteses diagnósticas anteriormente percebidas, enquanto que a psicopatologia fenomenológica perceberia o conjunto de sintomas e sinais vivenciados ao longo do tempo por T. como composição de um único e mesmo evento patológico, ou seja, o quadro de esquizofrenia.

Optamos por um terceiro entendimento. Embora reconheça a autonomia ontológica dos diagnósticos propostos anteriormente, que consideram o conjunto de sintomas e sinais como entidades psicopatológicas distintas, compatíveis com pânico e depressão, acreditamos que vê-los isoladamente acabe mascarando o fato de que possivelmente, eles representem, na totalidade existencial da paciente, sinalizadores de um mal maior. Ou seja, eles são um estatuto biograficamente contido dentro do diagnóstico de esquizofrenia que acomete T..

Com isso, queremos dizer que o diagnóstico de esquizofrenia, no caso de T., vai muito além da categorização de sintomas e sinais isoladamente; trata-se da interrupção do desenvolvimento biográfico da paciente pela emergência de eventos incompreensíveis, o que caracteriza a irrupção de um processo na linha vital que a quebra, modifica estável e longitudinalmente.

Para a psicopatologia fenomenológica, o sintoma isolado não importa. $\mathrm{O}$ que auxilia na construção de determinada hipótese diagnóstica é a inserção dos 
sintomas e sinais na totalidade biográfica. Somente o desenvolvimento global oferecerá sentido a determinado fenômeno no ciclo vital de um indivíduo.

Sendo assim, pode-se compreender que os eventos percebidos por T. e, posteriormente, pelo médico da família, como quadros de depressão e pânico são, na realidade, a eclosão de um conjunto de sintomas e sinais prodrômicos do quadro de esquizofrenia. Falamos, portanto, de uma hierarquia no diagnóstico do caso que ora apresentamos.

Retomemos o esboço da linha do tempo, apontando para o fato de que, em dado momento do ciclo vital de T., houve uma ruptura que comprometeu dramaticamente sua edificação mental de modo inequívoco e estável, a ponto de modificá-lo integralmente. Indica Messas (2010, p. 3) que “na patologia em sentido estrito, a estabilidade da estrutura é dada pela própria doença".

Nossa afirmação exige a reflexão sobre dois pressupostos caros à psicopatologia fenomenológica: os conceitos de processo e desenvolvimento, bem como a noção de compreensividade. Aspectos que embasam o apontamento para a hipótese diagnóstica que almejo aqui estabelecer.

Grosso modo, podemos conceituar processo como oposto ao conceito de desenvolvimento. A definição sugerida por Tamelini (2007, p. 141) reza que "processo é a alteração permanente do psiquismo, incompreensível, resultante do surgimento de algo novo". Em contrapartida ao conceito de processo, Dilthey sugere que o desenvolvimento é a conexão da totalidade da vida psíquica ao longo do tempo e processo a interrupção da continuidade compreensiva (Alonso-Fernández, 1976, p. 193).

Alonso-Fernández (1976), em seu "Fundamentos de La Psiquiatria Actual" retoma historicamente pontos importantes dos conceitos de Processo e Desenvolvimento, observando que Jaspers indica que é no desvio da evolução, e não na sintomatologia, que se estabelece determinado quadro psicopatológico, aspecto que diferencia Processo de Desenvolvimento. Eis, portanto, observações que desencorajam a construção de hipótese diagnóstica baseada unicamente na junção de sintomas e sinais analisados isoladamente.

A percepção de incapacitação progressiva e totalizante como marca do processo psíquico (Alonso-Fernández, 1976) é perceptível na linha vital de T., onde, cronologicamente, a partir de 1989, é possível visualizar a doença mental estendendo-se ao longo do tempo sobre a vida da paciente em diferentes instâncias. 
Pode-se, enfim, constatar o caráter de aparente irreversibilidade ${ }^{4}$ no quadro de T., qualidade que indica o agravamento mental que tipifica uma psicose processual: crise repentina após período inicial de estranhamento costumeiramente identificado pela paciente como "depressão" - para, então, se instaurar de modo expressivo, modificando a existência do indivíduo.

Verifica-se, assim, um comprometimento ascendente, inicialmente em sua vida profissional e relacional, que se estende de modo estável até atingir os aspectos mais básicos: as atividades da vida diária, como locomoção, independência nas ações de auto-cuidado, contato com o mundo externo, alimentação. Progressivamente, T. foi deteriorando-se. O sinal mais dramático resultante da deterioração sofrida pela paciente talvez esteja melhor representado na aparência corporal de sagui, conforme descrevemos anteriormente.

Interessante pensarmos neste "retorno" aos estágios anteriores do desenvolvimento evolutivo da espécie humana - nossa descendência dos macacos. O corpo de T. talvez testemunhe, exatamente, a qualidade da involução a partir da irrupção do processo sobre a estrutura vivida. T. é aquela que não pode seguir em frente, permanecer na linha do desenvolvimento, expandir-se.

Esse corpo de "criança do nordeste" com o qual T. tanto se identifica, desprovido de nutrição e paralisado numa infância que midiaticamente simboliza restrição é a representação concreta do grave transtorno mental que a atingiu em 1989. Um corpo que não pode realizar e que necessita de resguardo e quietude. Não posso me furtar de comentar a geografia eleita por T., quando se identifica com as crianças vitimadas pela seca do nordeste brasileiro.

Cabe aqui a inferência sobre a peculiaridade do território eleito por T. para simbolizar sua experiência corporal: ainda que estejamos no campo das catástrofes naturais, grandiosas representantes do mundo externo que ameaça e hostiliza T. e sua mãe, não se trata de uma geografia acometida pelo paroxismo dos terremotos e furacões, elementos externos de repentina destruição - foco comum do medo da paciente.

Esta descreve seu corpo assolado pelo sertão nordestino, território de uma catástrofe silenciosa e lenta, que jamais se anuncia: a seca. A seca depende

\footnotetext{
${ }^{4}$ Em "Reação vivencial patológica", Messas (2007) afirma que não podemos estabelecer conclusões fechadas sobre determinada investigação biográfica pelo fato de que, apenas com o encerramento da vida seria possível alcançar um conhecimento definitivo sobre o investigando. Ponderamos atualmente que nem mesmo o encerramento de uma biografia permite alcançarmos um conhecimento definitivo sobre o indivíduo, visto que toda investigação fenomenológica se dá através do testemunho do investigando/investigador. Trata-se sempre de uma produção de duas estruturas vividas, atravessadas pela singularidade biográfica de cada um.
} 
do tempo que passa, dos dias sem chuva, da inclemência do sol que, aos poucos, faz desaparecer riachos, mata a lavoura, emagrece o gado. Seca que não permite o desenvolvimento da vida. É através desta fala, mediada pelas imagens de uma televisão permanentemente ligada, que T. simboliza e percebe o fato patológico que a assola. Segundo Messas (2010, p.25):

O corpo é simultaneamente experiência de imposição e liberdade. Por meio dele reconhecemos aquilo do qual jamais estaremos libertos em nossa vida, como presença solidamente imposta de dentro; nesta seara incluem-se as determinações do próprio temperamento. No entanto, também é o corpo o instrumento para concretização de nossas aspirações e ideais de vida.

A indistinção com que T. trata eventos corporais e mentais, por vezes não estabelecendo a habitual fronteira cartesiana entre corpo e mente, como normalmente o fazem pacientes atendidos nos serviços de saúde e profissionais que acompanham os casos, esculpe, no corpo, a forma de uma biografia atravessada por dois tempos: o imediato e o gradual.

Esta integralidade de eventos somáticos e psíquicos tão bem alinhados e indistinguíveis revela a dificuldade que o atendimento em saúde pode enfrentar diante da complexidade de uma paciente cujo sofrimento psíquico compacta-se inexoravelmente na queixa somática. Trata-se de um corpo que encena a loucura de T., aspecto nem sempre comum em pacientes esquizofrênicos.

Se fizermos uma análise da temporalidade das referências metafóricas eleitas por T. ao descrever seu corpo, percebemos as linhas do imediato e do gradual tatuadas em sua biografia. Por um lado, o quadro patológico revela o desenho de uma calcinação gradual. Este mesmo aspecto foi identificado por Binswanger (1958) em sua análise do famoso caso de "Ellen West" como marca da esquizofrenia. Segundo este autor, a vitalidade que se esvai gradualmente é característica dos quadros esquizofrênicos. Neste caso, Binswanger analisa o progressivo esvaziamento da intensa vitalidade tão característica da protagonista do estudo a partir da emersão - aos vinte anos - do que, inicialmente, é identificado como uma "ideia fixa", ilustrada pelo medo de engordar. Todavia, o autor inicia seu estudo indicando que aos nove meses, Ellen negou-se a tomar leite, alimentando-se, desde então, de mingau.

Ao longo dos dezessete anos em que manteve o diário, Ellen testemunha, em diversas ocasiões, a sensação de se sentir pequena num mundo incompreensível. Identificamos na narrativa desta sensação de pequenez existencial frente a um mundo que se torna cada vez mais ilegível, o 
esvaziamento de sentido impondo-se longitudinal e progressivamente (marca do tempo gradual).

Aos vinte anos, passa a ser atormentada por um temor concreto de ganhar peso, acompanhado de outros eventos, como o pavor crescente da sensação de fome e a adoção de uma rotina de caminhadas intensas para se manter magra - evento que caracteriza a emergência do tempo imediato.Segundo Binswanger (1958, p. 294), Ellen

se queixa que não encontra a atividade que busca, que não tem paz, que experimenta verdadeiro tormento quando se sente sem fazer nada, que todos os seus nervos tremem e em geral repercutem em seu corpo todos os estremecimentos da alma. ${ }^{5}$

Ellen relata que, há cada ano, "vai perdendo um pouco de sua antiga força"6 (p. 297). Vivencia, já ao despertar pela manhã, o que chama de "terror depois de comer" (p. 307) que a acompanha ao longo do dia. Sente-se prisioneira dentro de si mesma (p.312). Binswanger observa que a corporeidade de Ellen

não deve confundir-se com a estrutura mortal ou com o corpo em seu sentido anatômico e anátomo-fisiológico; pelo contrário, deve-se entendê-la sempre no sentido existencial, a saber, como ser corporalmente, ou como ser-no-corpo, como já descrito repetidas vezes. (p. 342)

Acreditamos que aspectos basilares do estudo de caso Ellen West auxiliem na compreensão do caso T.: ao longo da narrativa de T., é possível identificar o esgotamento crescente que se estabelece na vida da paciente com a perda de sentido a partir de 1989. Trata-se de um distanciamento progressivo do mundo que, aos poucos, vai perdendo sentido: processo lento, irreversível e crescente. Falamos, portanto, de uma temporalidade que revela aquilo que Minkowski (2004) observou nos quadros esquizofrênicos e que cunhou como a perda gradual do contato vital com a realidade. Diz o autor:

Em vários pontos eu me afasto de Bleuler e mais particularmente, sob a influência de Bergson, eu vejo o transtorno inicial da esquizofrenia não em um afrouxamento de associações, mas na perda do contato vital com a realidade; é dessa perda de contato que eu tento deduzir os sintomas

5 Tradução da primeira autora para "se queja que no encuentra la actividade que busca, que no tiene paz, que experimenta verdadero tormento cuando se sienta sin hacer nada, que le tiemblan todos sus nervios y que en general repercuten en su cuerpo todos los estremecimientos de su alma".

6 Tradução da primeira autora para "Com cada año ' ha ido perdiendo um poco de su antigua fuerza". 
cardinais e as manifestações mais características da esquizofrenia." (Minkowski, 2004 p. 127).

Esta vitalidade que se esvai aos poucos e transforma a existência de T. e de Ellen num solo seco, pode, em seus momentos iniciais, ter sido percebido e nomeado pela paciente como a "depressão leve" à qual ela reiteradamente se refere. Cabe lembrar que Kraepelin compreendeu o quadro mórbido de Ellen West como melancolia (Binswanger, 1958). Diante deste interessante fato, cabe a interrogação: a experiência depressiva atravessada por $\mathrm{T}$. em determinado período da vida possui as mesmas características dos quadros depressivos vivenciados pelos indivíduos não esquizofrênicos?

$\mathrm{Na}$ depressão propriamente dita, veremos que ocorre igualmente um esgotamento. Todavia, trata-se de um esgotamento de um mundo que parece ser maior que o indivíduo; mundo ao qual ele não consegue mais corresponder. Entretanto, este mundo maior, não deixa de fazer sentido para o indivíduo. $\mathrm{O}$ sujeito sente-se aquém do mundo. O esgotamento esquizofrênico se relaciona com um mundo que, aos poucos, perde seu significado.

Concomitantemente a este descolamento do sentido do mundo, ocorre o estabelecimento da temporalidade do imediato. Percebo isso pelo horror ao súbito, presente no relato de T. quando descreve seus habituais objetos de medo - o tempo súbito que caracteriza a vivência de uma catástrofe. Eis outro ponto indicado por Binswanger (1958) como característica freqüente nos quadros esquizofrênicos: a angústia do que toma subitamente. Este aspecto foi nomeado por Mário Eduardo Costa Pereira, como pânico, pródromo, segundo o autor, do quadro esquizofrênico de West (Pereira, 2004).

Desta forma, verificamos que, tradicionalmente, a psicopatologia fenomenológica discute a possibilidade de que o contraste da vivência concomitante do esgotamento gradual - que conduz para baixo a existência do sujeito - com a temporalidade do imediato - a partir do medo intenso do que repentinamente brota -, seja a característica fundamental de uma esquizofrenia.

Um último aspecto que apontamos no presente estudo diz respeito a percepção de T. sobre o envenenamento que acredita ter sofrido em 1999, com doce de leite. Para isso, recorremos a Minkowski uma vez mais. Como anteriormente dito, Minkowski sugere que o aspecto fundamental da esquizofrenia é a perda de contato vital com a realidade. Mario Eduardo Pereira aponta que "é a partir dessa condição mórbida irredutível que o estado psicopatológico se instala e em torno do qual se implantam os sintomas secundários." (Pereira, 2004, p.128). Com base em Minkowski, afirma o autor brasileiro que é através do delírio, das alucinações e do comportamento bizarro 
que o indivíduo tenta compensar a desordem psíquica severa advinda da temporalidade do imediato e do gradual, presentes na esquizofrenia.

Baseando-nos nesse pressuposto, infiro que a convicção de T. de que fora envenenada talvez seja a tentativa de lidar patologicamente com a perda de sentido do mundo, evento incompreensível e ameaçador. Assim, a vida de T. abandona a linha do desenvolvimento, mutilada pela irrupção do processo. Eis possivelmente o envenenamento ao qual ela se refere.

\section{Conclusões}

O presente estudo buscou apresentar um caso clínico atendido na atenção primária, estabelecendo a discussão sobre o diagnóstico diferencial amparada no arcabouço teórico da Psicopatologia Fenomenológica.

Consideramos imenso o desafio aos profissionais que compõem as equipes da Estratégia Saúde da Família e dos Núcleos de Apoio à Saúde da Família: a qualificação das discussões técnicas sobre os casos de saúde mental atendidos na saúde pública. Construir, de modo criterioso, o entendimento sobre determinado quadro psicopatológico - sustentando o exercício reflexivo em equipe - não é tarefa fácil. Percebe-se que este fator ainda está longe de ser alcançado, embora os avanços e benefícios obtidos com o advento da ESF no Brasil sejam inegáveis.

A Estratégia Saúde da Família, eleita como porta de entrada preferencial para o Sistema Único de Saúde (Brasil, 1990), reorienta o modelo de atendimento através do trabalho em equipe, indicando o acompanhamento longitudinal de famílias localizadas em determinada área geográfica como o mais eficaz no manejo de agravos em saúde.

O NASF deve apoiar as equipes básicas, qualificando as ações de assistência, prevenção e promoção. Tem como tarefa primordial a sustentação das discussões técnicas dos casos atendidos em determinado território e os atendimentos compartilhados - valendo-se, para isso, dos dados epidemiológicos regionais.

Inequivocadamente, o SUS elege como modelo de assistência o acompanhamento do paciente por uma mesma equipe ao longo do tempo, tendo como fulcro a discussão e estudo dos casos de modo regular. Tais discussões são responsáveis pelo embasamento técnico de todas as ações de cuidado a determinada família/sujeito. 
Este modelo parece ir ao encontro do método fenomenológico, que enfoca o acompanhamento longitudinal e a necessidade de pensar sobre a vida do paciente, compreendendo os fatos que forjam sua biografia sem pressa. Infelizmente, percebe-se a primazia da assistência em saúde mental direcionada unicamente para a remissão de sintomas. Como resultado, assistimos a uma clínica que renuncia à investigação aprofundada sobre determinado evento patológico.

O acompanhamento longitudinal de determinado fenômeno vivenciado pelo paciente talvez seja a forma mais eficaz de estabelecer linhas de cuidado coerentes e menos fragmentadas, garantindo a integralidade da assistência aspecto ainda inadequadamente compreendido e que acarreta importante prejuízo na assistência conforme originalmente preconizada pelo SUS (Brasil, 1990).

\section{Referências bibliográficas}

Alonso-Fernández. (1976). Fundamentos de La Psiquiatria Actual. Madri: Editorial Paz Montalvo.

Associação Psiquiátrica Americana (APA). (2002). Manual Diagnóstico e Estatístico de Transtornos Mentais - Texto Revisado. Porto Alegre: Ed. Artmed.

Binswanger, Ludwig. (1958). El caso de Ellen West. In May, Rollo et al. Existencia: Nueva Dimensión em psiquiatría y psicología (p.289-434). Madrid: Editorial Gredos S.A..

Brasil. (1990). Lei 8.080/90 (Lei Orgânica da Saúde). Brasília, DF: Ministério da Saúde.

Dalgalarrondo, Paulo. (2008). Psicopatologia e Semiologia dos Transtornos Mentais. Porto Alegre: Artmed.

Messas, Guilherme. (2007). As Formas da Alteração Mental - Estudos Psicopatológicos. São Paulo: Casa do Psicólogo.

$$
\text { (2010). Ensaio Sobre a Estrutura Vivida - Psicopatologia }
$$
Fenomenológica Comparada. São Paulo: Ed. Roca.

Minkowski, Eugène. (2004). Breves reflexões a respeito do sofrimento (aspecto pático da existência). Pereira, Mario Eduardo. A perda do contato vital com 
a realidade na esquizofrenia segundo Eugène Minkowski, Revista Latinoamericana de Psicopatologia Fundamental, 7 (2), jun.

Pereira, Mario Eduardo. (2004). A perda do contato vital com a realidade na esquizofrenia segundo Eugène Minkowski. Revista Latinoamericana de Psicopatologia Fundamental, 7 (2), jun.

Tamelini, Melissa. (2007). Processo psíquico II. In Messas, Guilherme. As Formas da Alteração Mental - Estudos Psicopatológicos. São Paulo: Casa do Psicólogo. 